\title{
Climate change, food insecurity and chronic diseases: sustainable and healthy policy opportunities for Australia
}

\author{
Sharon Friel \\ Australian Research Council Future Fellow, The National Centre \\ for Epidemiology and Population Health, \\ The Australian National University \\ Email: Sharon.friel@anu.edu.au
}

\begin{abstract}
Food provides a link between the population health and climate stabilisation agendas. This paper argues that a broader view of food security for the 21 st century in Australia and internationally is needed - one that judges the food system for its nutritional quality, social value and impact on the environment. If done well, climate change mitigation and adaptation policies provide ways to achieve this. This paper focuses on mitigation strategies, and describes how the reduction of greenhouse gas emissions from the agricultural sector through a reduction in consumption of animal source foods can improve food security and reduce the levels of chronic diseases such as cardiovascular diseases and some cancers.
\end{abstract}

In the mid-1970s, the World Food Conference defined food security in terms of a food supply that could ensure the availability and price stability of basic foodstuffs at the international and national level: 'food security exists when all people, at all times, have physical and economic access to sufficient, safe and nutritious food to meet their dietary needs and food preferences for an active and healthy life.'

This paper argues the need to expand the framing of food security to include not just quantity of food but also its nutritional quality, the wider social context and environmental dimensions. By using such a framing, food insecurity would encompass both a lack of food and a lack of good nutrition. The definition of food and nutrition insecurity encompasses the unhealthy transition from plant-based diets to diets of highly refined foods and meat and dairy products that contain high levels of saturated fats; a transition that is occurring in all but the poorest countries. ${ }^{2}$ A more comprehensive understanding of food insecurity also recognises that it is not just nutritional health that is compromised in foodpoor households, but also social behaviour when, due to issues of affordability and access, people cannot eat, shop for, provide or exchange food in the manner that has become the acceptable norm in society. ${ }^{3}$ The paper emphasises the critical relationship between climate change and the food system, with consequences for food security, dietary options and chronic disease risks among different social groups.

The paper also discusses how food security in 21 st century Australia and internationally requires the focus of food policy to evolve from seeking to increase the amount of food available for consumption, to also consider wider public health and environmental consequences.

\section{Food insecurity in a country like Australia}

The world faces high levels of food insecurity; while 1 billion people have insufficient calorie or protein intake and experience undernutrition in relation to micronutrients; in many countries, poor nutritional quality and an excess calorie intake has caused a global obesity epidemic. ${ }^{4}$

\section{Insufficient food}

In Australia a substantial proportion of the population are nutritionally compromised through lack of food: $15 \%$ of young people, $20 \%$ of people in the second lowest income quintile and rental households, $23 \%$ of unemployed and single parent households, ${ }^{5} 71 \%$ of refugees resident in Australia for less than a year, ${ }^{6}$ and $7 \%$ of the general population surveyed in South Australia ${ }^{7}$ reported having run out of food at times during the previous 12 months and not being able to buy more. In New South Wales (NSW), $5.3 \%$ of people aged 16 years and over experienced food insecurity in $2005 .^{8}$ The prevalence is much higher among socially disadvantaged households; $22 \%$ of low income households in South West Sydney reported having run out of food at times during the previous 12 months and not being able to buy more. ${ }^{9}$

\section{Nutritional insecurity}

A significant proportion of the Australian population while not lacking sufficient food, consume a diet that is 
nutritionally imbalanced, leading to nutrition insecurity. For example, in 1995 (the most recent nutrition survey for Australia), saturated fat accounted for around $13 \%$ of total energy intake by Australian adults, higher than the recommended maximum level of 10\%. Analysis of the 2004-05 National Health Survey shows that $86 \%$ of people aged 12 years and over consumed fewer than the National Health and Medical Research Council recommended five serves of vegetables per day, and $46 \%$ consumed fewer than two serves of fruit. ${ }^{10}$

\section{The relationship between food insecurity and chronic diseases}

Diet plays a prominent role in premature death from many chronic health conditions. Undernutrition leads to increased susceptibility and reduced resilience to chronic diseases and cognitive dysfunction among nutritionally compromised populations. Overconsumption together with a reduction in physical inactivity are among the leading causes of obesity, cardiovascular disease, type 2 diabetes and certain types of cancers. $^{11,12}$

Almost a quarter of Australia's disease burden is attributable to diet-related risk factors. ${ }^{10}$ Although declining between 1987 and 2006, cardiovascular disease remained the most common cause of death in NSW in 2006 (16245 deaths). A proportion of the non-communicable diseases that dominate the NSW health burden (Figure 1) ${ }^{13}$ could be prevented through action which seeks to ensure food and nutrition security.

\section{Food, social systems and food insecurity}

The nature of the global and Australian food systems from the underlying conditions of governance and trade, issues of agricultural production, food procurement and distribution, consumer price of food, excessive marketing of energy-dense, nutrient-poor foods and food waste affects food security and health risk through matters of food availability, nutritional quality and affordability. ${ }^{14}$

Like most other risk factors for chronic diseases in Australia, food insecurity is more prevalent among socially disadvantaged groups. Having enough money to buy food; being able to travel to retail outlets selling the range of commodities desired in contemporary societies; having food storage and cooking facilities; enjoying a choice of cuisines and food practices appropriate to one's cultural identity; and having the personal skills and knowledge to prepare nutritionally balanced meals influence the social distribution of food and nutrition security and thereby chronic disease risk. ${ }^{15}$

\section{Climate change - an additional determinant of food insecurity}

In addition to existing food and social system inadequacies, there is growing recognition of the additional stress on food insecurity presented by climate change. The drought-prone and long-term drying conditions in Australia and in other subtropical regions around the world, higher temperatures, rising sea levels, increasing frequency of flooding, and
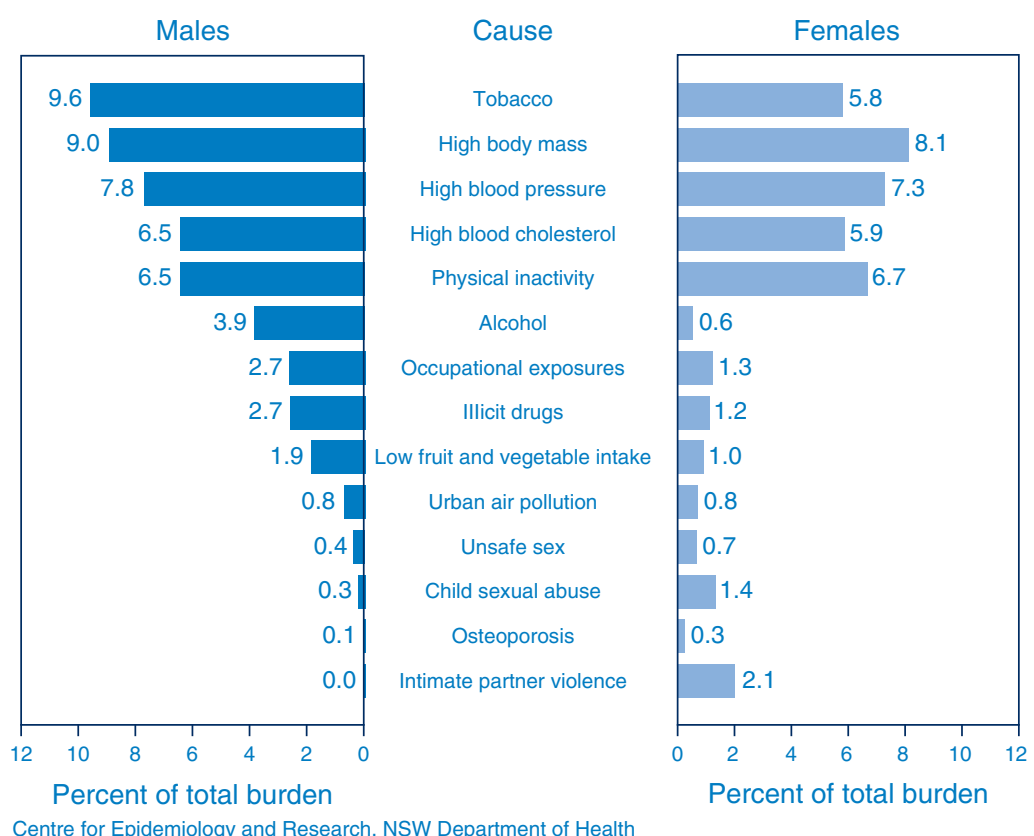

Figure 1. Disability adjusted life years for males and for females, by risk factor, NSW 2003.

Source: The health of the people of New South Wales - Report of the Chief Health Officer. Sydney: NSW Department of Health. Population Health Division; 2008. 
acidification of oceans contribute to impaired yield, quality and affordability of food in many countries. ${ }^{16}$ Further, climate change-induced disturbances to traditional living, hunting and eating patterns among rural and remote Indigenous populations may also affect food security through reduced options for physical mobility and increased reliance on imported energy-dense processed foods, thus potentially amplifying obesity, cardiovascular disease and diabetes. ${ }^{17}$

In Australia climate change is affecting the availability and price of food. Usually one of the world's largest grain exporters, severe drought in the last decade has led to two years (2001-02 and 2007-08) of net grain importing. ${ }^{18}$ Similarly, fresh food such as fruit and vegetables are produced and distributed largely domestically however prolonged drought and the frequency of climate changeinduced extreme weather events affect the availability of fruits and vegetables and therefore the consumer price. A recent report estimated that between 2005 and 2007 there had been a $33 \%$ increase in the price of vegetables and a $43 \%$ increase in fruit prices because of the drought. ${ }^{19}$

Rising food prices most affect the poor. In Australia, the cost of consuming a diet based on national health guidelines already uses about $40 \%$ of the disposable income of welfare-dependent families compared to $20 \%$ of an average income household. ${ }^{20}$ Climate change-related additional price increases will add potentially unmanageable financial pressures on some households, leading to food insecurity as well as physical and mental distress. As the cost of the collective basket of household goods starts to increase more rapidly, and income does not, all but the wealthy in Australia and elsewhere will likely feel the effects, putting substantially more people at risk of food insecurity. ${ }^{21}$

\section{The food system's contribution to climate change}

There is a bi-directional relationship between climate change and food systems. All stages in the food system produce greenhouse gases and therefore contribute to climate change. The agricultural production stage represents the single biggest contributor to the overall food sector emissions. According to calculations by the Intergovernmental Panel on Climate Change (IPCC) agriculture along with the associated deforestation and land use changes account for about $29 \%$ of global emissions. ${ }^{22,23}$ Production of foods from animal sources (livestock) is the major contributor to emissions from the agricultural sector.

In Australia, $16.3 \%$ (88.1 metric tonne carbon dioxide equivalent [MtCO2-e]) of the total 541.2 million $\mathrm{MtCO} 2-\mathrm{e}$ emitted in 2007 came from the agriculture sector (this figure excludes agriculture-associated land use change greenhouse gas emissions). ${ }^{24}$ NSW's agriculture sector produced 17.5 MtCO2-e in the same time period - the second largest contribution by the States and Territories to greenhouse gas emissions from the agriculture sector. ${ }^{25}$ Australia's livestock emissions were 61.0 MtCO2-e in 2007 , representing $69 \%$ of the sector's total emissions (Figure 2).

Livestock give rise to nitrous oxide, both from pasture land and from the arable land used to grow feed crops and methane, from digestive processes of ruminant animals. This enteric fermentation process by ruminant animals is by far the biggest contributor to carbon dioxide equivalent emissions in Australia (57.6 MtCO2-e in 2007). It is both the volume of emissions associated with ruminant animals that are a concern and the type of emissions (the global warming potential of methane is 23 times that of carbon dioxide). The emissions per unit of livestock product vary

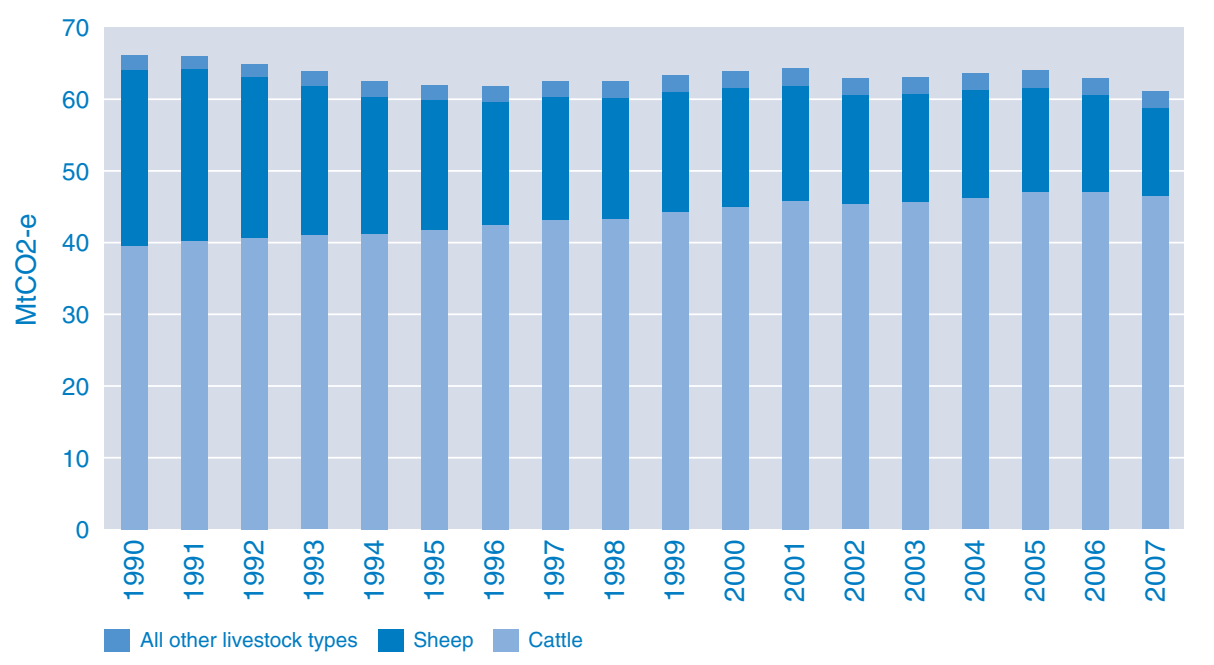

Figure 2. Trends in metric tonne carbon dioxide equivalent $\left(\mathrm{MtCO}_{2}\right.$-e) emissions from livestock, Australia.

Source: Department of Climate Change. National Greenhouse Gas Inventory accounting for the KYOTO target. Canberra: Department of Climate Change; 2009. 
according to the type of animal and the feeding regimen used, but appear higher in beef, sheep and dairy compared with poultry farming. ${ }^{24}$

In combination with world population growth projections, the increasing demand for agriculturally intensive animal foods, such as meat and dairy products, point to an approximate doubling in global meat consumption by the mid-21st century. ${ }^{26}$ This has serious ramifications for climate change and local environments. It is also a concern for food security and human health. ${ }^{27}$ While animal-source products are important sources of essential macro and micro nutrients, they are also significant contributors of saturated fats in the human diet and of cardiovascular disease. ${ }^{11}$ Colorectal cancer is also strongly related to levels of animal-source dietary intake, particularly red meat. ${ }^{28}$

\section{Improving food security through climate change mitigation policy}

As described, many of the underlying causes of food insecurity and chronic diseases are also greenhouse gasemitting processes. ${ }^{29}$ Actions to mitigate climate change are therefore actions that prevent the growth of food insecurity and the associated disease burden in Australia and globally.

Given that the agricultural production stage represents the single biggest contributor to the food system's total emissions and that the bulk of emissions from agriculture are due to livestock production, a key strategy to mitigate climate change - in Australia and other high income countries - would sensibly focus in this area. A recent international research program on the health co-benefits that would result from actions to reduce greenhouse gas emissions in a number of different sectors identified that, combined with technological improvements in farming practices, a $30 \%$ reduction in production and populationlevel consumption of animal-source foods would be needed to meet select national emissions targets. ${ }^{30}$ Modelling the health effects of a $30 \%$ reduction in consumption of animalsource foods (the major dietary source of saturated fat) estimated a $15 \%$ reduction in the years of life lost from ischaemic heart disease in the United Kingdom and 16\% in Sao Paulo, Brazil. ${ }^{31}$ Given that animal-source foods and associated saturated fats are common risk factors for other non-communicable diseases, dietary change would not only prevent ischaemic heart disease but also some cancers and possibly reduce obesity.

A forthcoming paper using Australia as a case study describes the modelled effects of a theoretical reduction in ruminant red meat consumption on colorectal cancer incidence in Australian adults and on greenhouse gas emissions from on-farm activities in the livestock sector. Under a scenario of $50 \mathrm{~g} /$ person/day red meat consumption, ${ }^{27}$ the estimated preventable proportion for colorectal cancer incidence among males was $10.7 \%$ (771 cases in 2005), while reducing annual emissions from livestock by 13.3 MtCO2-e (approximately 22\% of emissions). ${ }^{32}$

\section{Conclusion}

Food security is no longer only about making food available, accessible and affordable. Climate change and the implications for the type and cost of foods available to Australians as well as preventing further dangerous climate change mean that sustainability must be placed at the heart of the food system. As Lang describes, this means judging food production and consumption for their impact on the environment, health, quality and social values. ${ }^{33}$ Climate change mitigation policy provides a major opportunity to improve food security and human health as well as planetary health.

\section{References}

1. Food and Agriculture Organization. Rome declaration on world food security and World Food Summit plan of action. Rome: Food and Agriculture Organization of the United Nations; 1996.

2. Popkin BM. Global nutrition dynamics: the world is shifting rapidly toward a diet linked with noncommunicable diseases. Am J Clin Nutr 2006; 84(2): 289-98.

3. Dowler E. Food Poverty and Food Policy. IDS Bull 1998; 29(1): 58-65. doi:10.1111/j.1759-5436.1998.mp29001007.x

4. Food and Agriculture Organization. The State of Food Insecurity in the World. Rome: Food and Agriculture Organization of the United Nations; 2009.

5. Burns C. A review of the literature describing the link between poverty, food insecurity and obesity with specific reference to Australia. Melbourne: VicHealth; 2004.

6. Gallegos D, Ellies P, Wright J. Still there's no food! Food insecurity in a refugee population in Perth, Western Australia. Nutr Diet 2008; 65: 78-83. doi:10.1111/j.1747-0080.2007. 00175.x

7. Foley W, Ward P, Carter P, Coveney J, Tsourtos G, Taylor A. An ecological analysis of factors associated with food insecurity in South Australia, 2007. Public Health Nutr 2010; 13(02): 215-21. doi:10.1017/S1368980009990747

8. NSW Department of Health. New South Wales Population Health Survey 2005: Food insecurity in the last 12 months by socioeconomic disadvantage, persons aged 16 years and over. Sydney: Centre for Epidemiology and Research, NSW Department of Health; 2005.

9. Sydney Food Fairness Alliance. Understanding food insecurity: Why families go hungry in an affluent society: Sydney Food Fairness Alliance and Food Fairness Illawarra. (Accessed May 2010.)

10. AIHW. Australia's Health 2008. Canberra: Australian Institute of Health and Welfare; 2008.

11. World Health Organization. Diet, nutrition and the prevention of chronic diseases. Report of a joint WHO/FAO expert consultation. Technical Report Series 916. Geneva: World Health Organization; 2003. 
12. Seligman H, Laraia B, Kushel M. Food insecurity is associated with chronic disease among low-income NHANES participants. $J$ Nutr 2010; 140: 304-10. doi:10.3945/jn.109.112573

13. NSW Department of Health. The health of the people of New South Wales - Report of the Chief Health Officer. Sydney: NSW Department of Health. Population Health Division; 2008.

14. Hawkes C, Blouin C, Henson S, Drager N, Dube L. Trade, food, diet and health: perspectives and policy options. Oxford: Wiley-Blackwell; 2010.

15. Friel S, Baker P. Equity, food security and health equity in the Asia Pacific Region. Asia Pac J Clin Nutr 2009; 18(4): 620-32.

16. United Nations Development Programme. Human Development Report: Fighting climate change: human solidarity in a divided world. New York: United Nations Development Programme; 2007.

17. Furgal C, Seguin J. Climate change, health and vulnerability in Canadian northern Aboriginal communities. Environ Health Perspect 2006; 114: 1964-70.

18. Butler C. Food security in the Asia-Pacific: climate change, phosphorus, ozone and other environmental challenges. Asia Pac J Clin Nutr 2009; 18(4): 590-7.

19. Quiggin J. Drought, climate change and food prices in Australia. Melbourne: Australian Conservation Foundation; 2010.

20. Kettings C, Sinclair A, Voevodin M. A healthy diet consistent with Australian health recommendations is too expensive for welfare-dependent families. Aust N Z J Public Health 2009; 33: 566-72. doi:10.1111/j.1753-6405.2009.00454.x

21. Lobstein T, Friel S, Dowler E. Food, fuel and NCDs. Lancet 2008; 372: 628. doi:10.1016/S0140-6736(08)61270-2

22. Smith P, Martino D, Cai Z, Gwary D, Janzen H, Kumar P et al Greenhouse gas mitigation in agriculture. Philosoph Trans Roy Soc 2008; 262: 780-813.

23. Bellarby F, Hastings S. Cool farming: Climate impacts of agriculture and mitigation potential. Aberdeen: Report produced by the University of Aberdeen for Greenpeace; 2008.
24. Department of Climate Change. National Inventory Report 2007, Volume 1. Canberra: Department of Climate Change; 2009.

25. Department of Climate Change. Australian National Greenhouse Accounts: State and Territories Greenhouse Gas Inventories. Canberra: Department of Climate Change; 2007.

26. Food and Agriculture Organization. Livestock's Long Shadow - Environmental Issues and Options. Rome: Food and Agriculture Organization; 2006.

27. McMichael A, Powles J, Butler C, Uauy R. Food, livestock production, energy, climate change and health. Lancet 2007; 370: 1253-63. doi:10.1016/S0140-6736(07)61256-2

28. World Cancer Research Fund. Food, nutrition, physical activity, and the prevention of cancer: a global perspective. World Cancer Research Fund; 2007.

29. Friel S, Marmot M, McMichael A, Kjellstrom T, Vågerö D. Global health equity and climate stabilisation - need for a common agenda. Lancet 2008; 372: 1677-83. doi:10.1016/ S0140-6736(08)61692-X

30. Haines A, McMichael A, Smith K, Roberts I, Woodcock J, Markandya A et al. Public health benefits of strategies to reduce greenhouse-gas emissions: overview and implications for policy makers. Lancet 2009; 374: 2104-14. doi:10.1016/S0140-6736 (09)61759-1

31. Friel S, Dangour AD, Garnett T, Lock K, Chalabi Z, Roberts I et al. Public health benefits of strategies to reduce greenhousegas emissions: food and agriculture. Lancet 2009; 374: 2016-25. doi:10.1016/S0140-6736(09)61753-0

32. Butler A, Clements M, Friel S, McMichael A. Climate change mitigation by reduction of red meat consumption: estimated 'co-benefit' reduction in colorectal cancer incidence in Australia. Int J Epidemiol (forthcoming 2010).

33. Lang T. Conclusion - big choices about the food system. In: Lawrence G, Lyons K, Wallington T, editors. Food Security, Nutrition and Sustainability. London: Earthscan; 2010. 